\title{
Modelling and Simulation of Flexible Beam as Aerator to Generate Dissolved Oxygen in Water
}

\author{
Badrul Aisham Md Zain ${ }^{1,2, a}$, Muhammad Amir Mat Shah ${ }^{2, b}$, Ong Pauline $e^{2, c}$ \\ and Noormaziah bte Jafferi ${ }^{2, d}$ \\ ${ }^{1}$ Advance Control \& Automation Research (ADCARe) \\ ${ }^{2}$ Faculty of Mechanical Engineering \& Manufacturing Universiti Tun Hussein Onn Malaysia \\ (UTHM), 86400 Parit Raja, Batu Pahat, Johor, Malaysia \\ aaisham@uthm.edu.my, bHD100111@siswa.uthm.edu.my, 'ongp@uthm.edu.my, \\ normazia@uthm.edu.my
}

\section{Keyword: Flexible Beam, Dissolved Oxygen, Aerator}

\begin{abstract}
This paper presents the simulation of the flexible aerator model as a new concept to generate dissolved oxygen. This method is implementing the flexible beam motion as a medium to circulate water and create wave. This paper is using the simulation to optimize the suitable parameters namely the length of flexible beam and the percentage of immerse in water. The best result of dissolved oxygen level were found during run the flexible beam aerator at $12 \mathrm{~V}$ with $0.65 \mathrm{~m}$ length of flexible beam and immerses $25 \%$ in water. The flexible beam was successfully implemented as a new aerator concept where it is able to generate oxygen up to $8.6 \mathrm{mg} / \mathrm{L}$ with the average Standard Oxygen Transfer Efficiency $1.84 \mathrm{kgO}_{2} / \mathrm{kWhr}$
\end{abstract}

\section{Introduction}

Oxygen is essential to life critical to the survival of aquatic plants and animal. Shortage of dissolved oxygen is harmful to the fish. The dissolved oxygen comes from many sources, but the largest source of oxygen is absorbed from the atmosphere [1] [2]. Aeration and splashing allows more oxygen to be absorbed into the water. A second major source of oxygen is aquatic plants, including algae. During photosynthesis plants remove carbon dioxide from the water and replace it with oxygen.

Oxygen is continuously moving between the water and the surrounding air. The direction and speed of this movement is dependent upon the amount of contact between the air and water. The widely water's surface is exposed to the air the higher absorption of oxygen from the atmosphere than a calm, smooth body of water [3]. This is the idea behind aerators.

\section{Flexible beam}

Flexible beam is one of the important parts in robotic manipulator research study. It may offers a lower production cost due to weight of material used, larger work volume, higher operational speed, greater payload-to-manipulator weight ratio, smaller actuators, lower energy consumption, better maneuverability, better transportability and safer operation due to reduced inertia.

By using a control algorithm, the elastic deformations of the endpoint of the beam can be controlled and the vibration that was produced from the flexible beam will give benefit for this new aerator. It has the potential to offer a new concept of aeration by creating bubbles and wave on the surface of water.

A schematic diagram of flexible beam system is shown in Figure 1 where $\mathrm{X}_{0} \mathrm{OY}_{0}$ and $\mathrm{XOY}$ represent the stationary and moving coordinates of flexible beam, respectively. Torque applied at the hub was represented by $\tau(\mathrm{t})$ and $\mathrm{M}_{\mathrm{p}}$ is the payload mass at the end point of flexible beam. $\mathrm{I}_{\mathrm{h}}$ is the hub inertia and E, I and $\rho$ represent the Young's modulus, second moment of inertia and mass 
density per unit length of the flexible beam respectively. Flexible beam is confined to the XOY plane and the gravity effect to it movement was neglected.

The flexible beam system can be modeled as a pinned free flexible beam under the assumption of simple beam theory, which is valid when the ratio between beam's length and its height is relatively larger $(>10)$ and if the beam dose become too wrinkled because of flexure [4].

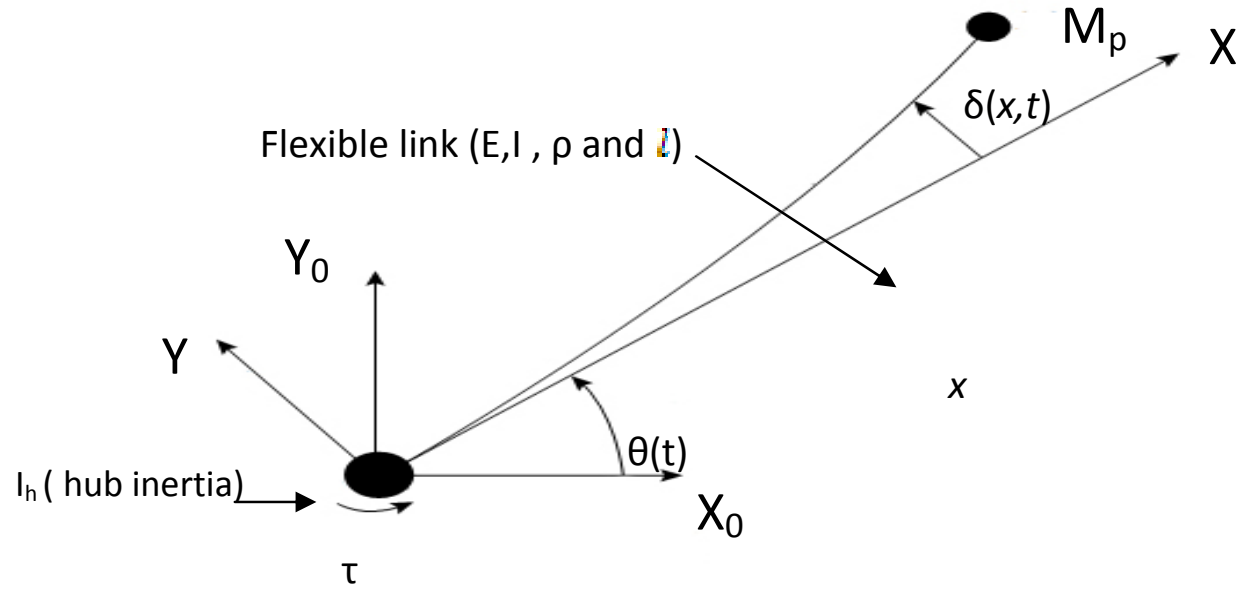

Fig. 1: Schematic Model of the Flexible beam

For an angular displacement, $\theta$ and elastic deflection, $\delta$, the total (net) displacement $y(x, t)$ of point along the flexible beam at a distance from the hub can be describe as a function of both the rigid body motion $\theta(t)$ and elastic deflection $\delta(x, t)$, measured form the line $\mathrm{OX}$;

$$
y(x, t)=x \theta(t)+\delta(x, t)
$$

The fourth-order partial differential equation (PDE) for the flexible beam motion can be obtained as equation(1). Associated with kinetic, potential and dissipated energies of the system, extended principle of the dynamic equation of motion for the flexible beam had been made by Hamilton (as shown in equation (2)), and the effects of rotary inertia and shear deformation are ignore [6].

$$
E I \frac{\partial^{4} w(x, t)}{\partial x^{4}}+\rho \frac{\partial^{2} w(x, t)}{\partial t^{2}}=-\rho x \ddot{\theta}
$$

To obtain the corresponding boundary condition, the following condition must follow:

- The displacement at the hub $\delta(x, t)$ must be zero.

- The total with the applied torque must be the same force at the hub.

- The mass $\mathrm{M}_{\mathrm{p}}$ at end point must equal to the shear force.

- The end point should not have any external force and the stress at the end point must be zero.

$$
\begin{aligned}
& w(0, t)=0 ; \quad E I \frac{\partial^{2} w(1, t)}{\partial x^{2}}=0 \\
& I_{h} \frac{\partial^{3} w(0, t)}{\partial t^{2} \partial x}+E I \frac{\partial^{2} w(0, t)}{\partial x^{2}}=\tau(t)-F_{d}(t) \mathrm{L} ; \quad M_{p} \frac{\partial^{2} w(l, t)}{\partial t^{2}}-E I \frac{\partial^{2} w(l, t)}{\partial x^{2}}=0
\end{aligned}
$$

The length of flexible beam represent by $l$. The equation (3) is the corresponding boundary conditions for equation (2) that represents the dynamic equation of motion of the flexible beam system. When a situation of interaction and contact between solid bodies with a fluid occur it yields drag force [4]. The drag force is a function of the fluid velocity and density along with the object's reference area and drag coefficient. The drag coefficient may further be a function of the Reynolds 
number. Reynolds number depends on the fluid density, viscosity, and velocity as well as the object's characteristic length. The drag equation can be defined as:

$$
F_{d}=0.5 \rho v^{2} C_{d} A
$$

where $F_{d}$ is the drag force in series with the direction of the flow velocity. Mass density of the fluid is represented by $\rho$ and velocity of the object relative to fluid is represented by $v$. Meanwhile $C_{d}$ and $A$ represent the reference area of object relative to the fluid and the drag coefficient respectively.

The drag coefficient of any object comprises the effects of two basic contributors to fluid dynamic drag: skin friction and form drag. The drag coefficient of a lifting airfoil or hydrofoil also includes the effect of lift-induced drag, while the drag coefficient of a complete structure such as an aircraft includes the effect of interference drag. Shape has a very large effect on the amount of drag produced [5] and different shapes indicate different drag coefficients. The common values for drag coefficient used are flat plate has $\mathrm{C}_{\mathrm{d}}=1.28$, wedge shaped prism with the wedge facing downstream has $C_{d}=1.14$, sphere has a $C_{d}$ that varies from 0.07 to 0.5 , a bullet $C_{d}=0.295$ and a typical airfoil $\mathrm{C}_{\mathrm{d}}=0.045$.

\section{A. $\quad$ Selecting suitable flexible beam length}

In the simulation, various lengths of flexible beam were tested to propose the most suitable length that can be used to operate the aerator. It is much easier to conduct using simulation. After intense iteration and trial and error on several flexible beam lengths, the most suitable length was determined.

The lengths were selected by considering the capability torque from the motor driver. Since the aerator motor's torque is $3.5 \mathrm{Nm}$, the mass load depends on the length of flexible beam including the additional loads exist from the water drag force. It also depends on level of immersion of flexible beam in water.

The simulations were set initially at $75 \%$ immersion level in water and running at full speed. Initial length of $0.50 \mathrm{~m}$ was used and increasing until the angular displacement of the flexible beam end point becomes unstable. When the length increased, the deflection at the end point was increased and at the same time the water drag force also increased and burden the driver motor. As the carried load become too heavy, the end point will face more resistance and difficult to reach rigid angular displacement consistently.

The result in Figure 2 shows the flexible beam aerator become unstable when simulated using length of $0.72 \mathrm{~m}$ and it continuously became more unstable when the length kept increasing. It was proven that, $0.72 \mathrm{~m}$ is the maximum length the driver motor capable to handle. The end points of flexible link showed inconsistent range of angular displacement which is due to maximum carried load as the motor reached maximum torque. From this simulation, it can be concluded that, the most suitable length to be used by flexible beam aerators was below $0.72 \mathrm{~m}$. Selected lengths of flexible beam further used in this simulation were $0.45 \mathrm{~m}, 0.55 \mathrm{~m}$ and $0.65 \mathrm{~m}$.

\section{Simulink Model}

Matlab Simulink software is used to simulate the flexible beam aerator mathematical model. The parameters need to be known are length of plate and the percentage of immersing plate in water and the 


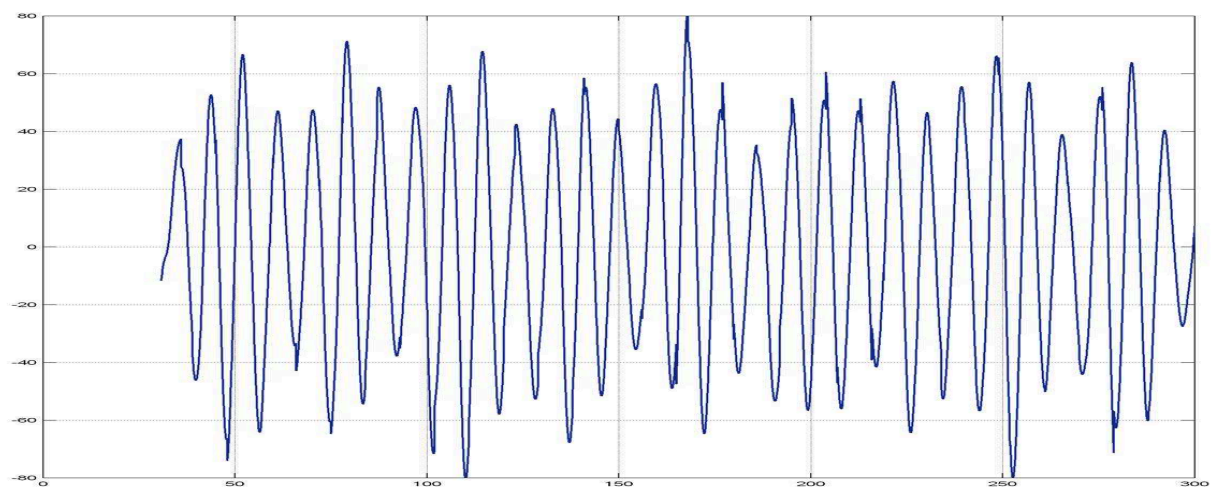

Fig. 2: Oscillation of angular displacement when used a maximum length of flexible link

amount of torque required. State space formulation is used to simulate dynamic equation of the flexible beam with matrix formulation. Using the notation for simulation of discrete-time linear systems, the dynamic equations of the flexible beam can be written as [6]:

$$
\begin{aligned}
& x(n+1)=P x(n)+Q u, \\
& y(n)=R x(n)+S u, \\
& P=\left[\begin{array}{c:c}
A & B \\
I_{N \times N} & O_{N \times N}
\end{array}\right], \quad Q=\left[\begin{array}{c}
C \\
O_{N \times 1}
\end{array}\right], \quad R=\left[I_{N} O_{N}\right], \quad S=\left[O_{2 N}\right] \\
& \mathbf{F}=\left[\begin{array}{llll}
K_{6} & 0 & \ldots & 0
\end{array}\right]^{T} ; u=\left[\begin{array}{llll}
\tau & 0 & \ldots & 0
\end{array}\right]^{\mathrm{T}} ; \\
& y(n)=[\mathrm{x}(1, \mathrm{n}) \ldots \quad x(N, n), \quad x(1, n-1) \quad \ldots \quad x(N, n-1)], \text { where } \mathrm{N} \text { represents the number of sections. }
\end{aligned}
$$

Figure 3 shows the Simulink model of the Flexible Link Aerator. Input for this simulation model is applied torque. Output from the state space in this simulation model shows the position of flexible beam deflection in water. Input In 1 represents the input for voltage and torque of the motor, and input In 2 represent the drag force and water resistance. Result of angular displacement will then be mixed with input of drag force and water resistance again. Output 1 represents the dissolved oxygen estimator.

At dissolved oxygen estimator, the generated dissolved oxygen can be estimated according to the speed movement, and area of length of flexible beam contact with water.

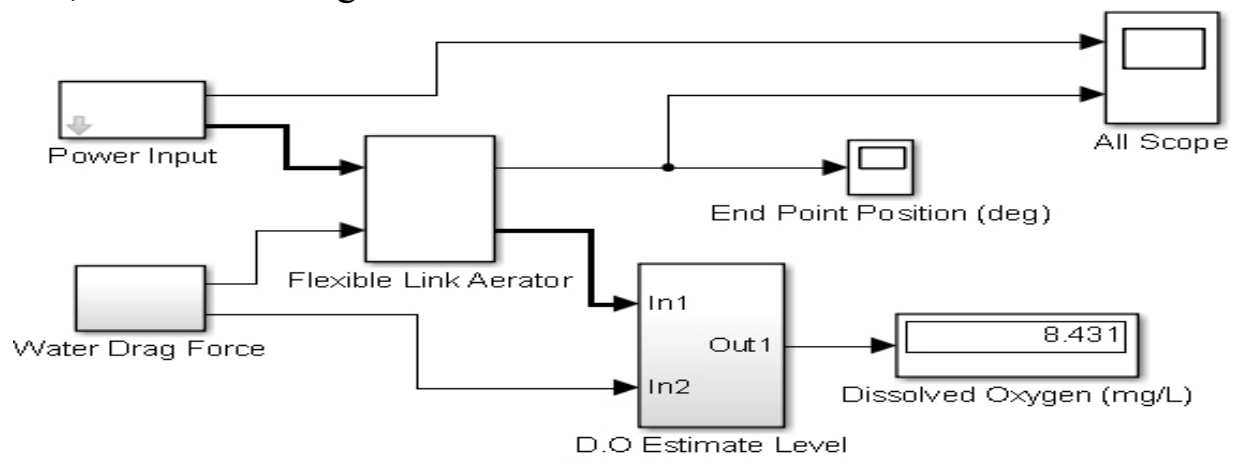

Fig. 3: Simulink model of the Flexible Link Aerator

\section{Result}

The estimated maximum dissolved oxygen generated using flexible beam of length $0.45 \mathrm{~m}, 0.55 \mathrm{~m}$ and $0.65 \mathrm{~m}$ is about $6.582 \mathrm{mg} / \mathrm{L}, 7.457 \mathrm{mg} / \mathrm{L}$ and $9.065 \mathrm{mg} / \mathrm{L}$ respectively, as shown in Figure 4 . These three generated dissolved oxygen levels were above the critical level $4 \mathrm{mg} / \mathrm{L}$. However, the 
parameter setting resulting in the highest dissolved oxygen level was selected due to its utmost performance. Thus, according to the result of this simulation, the flexible link of length $0.65 \mathrm{~m}$ is selected as the optimum length for flexible link aerator.

Figure 5 shows the simulation results of the aerator at full speed with $0.65 \mathrm{~m}$ length of flexible beam. Different percentage of the level of immerse was applied, started with $25 \%$ of immerse level and followed by $50 \%$ and $75 \%$, respectively. Figure 4 also shows that the generated dissolved oxygen is associated to the different percentages of immerse water levels of the flexible beam. Simulations at $25 \%$ of immerse water level shows the best result, where the estimated dissolved oxygen generated is $9.065 \mathrm{mg} / \mathrm{L}$. The estimated value of dissolved oxygen decrease to $8.626 \mathrm{mg} / \mathrm{L}$ and $8.059 \mathrm{mg} / \mathrm{L}$, when the percentage of immerse water level increase to $50 \%$ and $75 \%$, respectively.
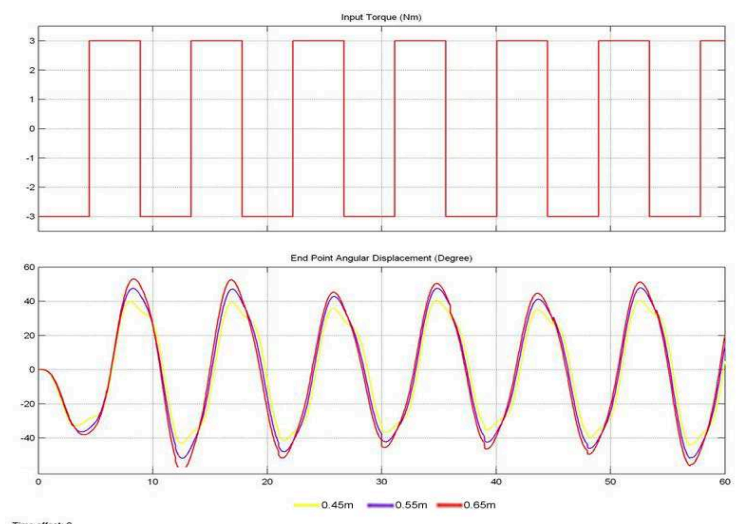

(a) Aerator with different length

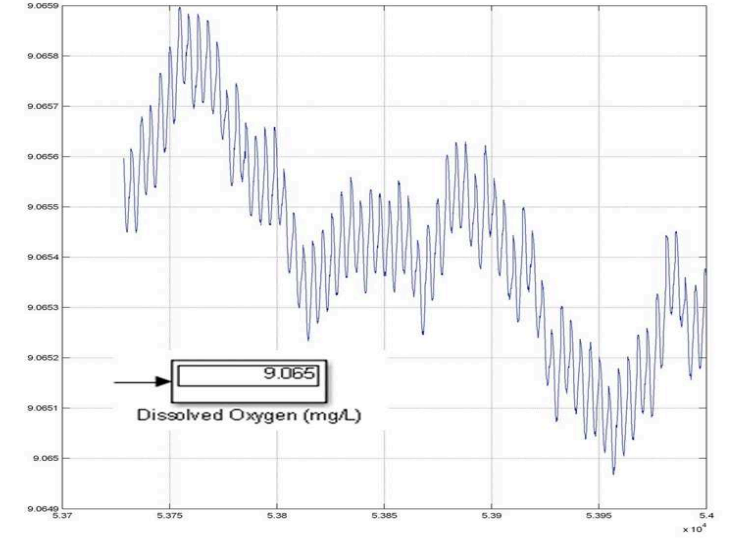

(b) Estimated maximum Dissolved Oxygen with $0.65 \mathrm{~m}$

Fig. 4: Simulation of aerator and estimated maximum Dissolved Oxygen with different lengths of flexible beam

\section{Conclusion}

This new concept aerator proves that flexible beam is able as aerator to generate dissolved oxygen up to $8.6 \mathrm{mg} / \mathrm{L}$ with the average Oxygen Transfer Efficiency value of $1.84 \mathrm{kgO}_{2} / \mathrm{kWhr}$. The successful result is achieved by using the optimum value of setup where the full voltage $12 \mathrm{~V}$ is used to run the aerator at full speed with the longest length is 0.65 meter and suitable level to immerse the flexible beam is between 15 to 50 percent in water.

\section{Acknowledgement}

Financial support from Universiti Tun Hussein Onn Malaysia (UTHM) through Short Term Grant Vot 1287 is gratefully acknowledged. 

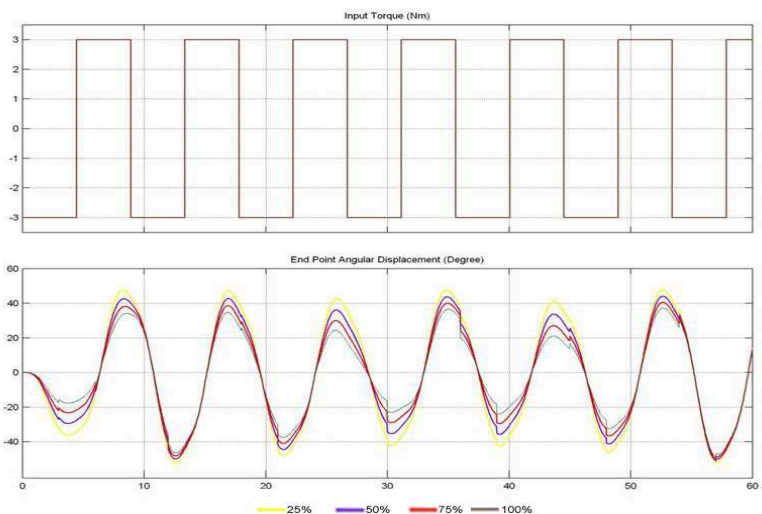

(a) Different percentage of immerse in water

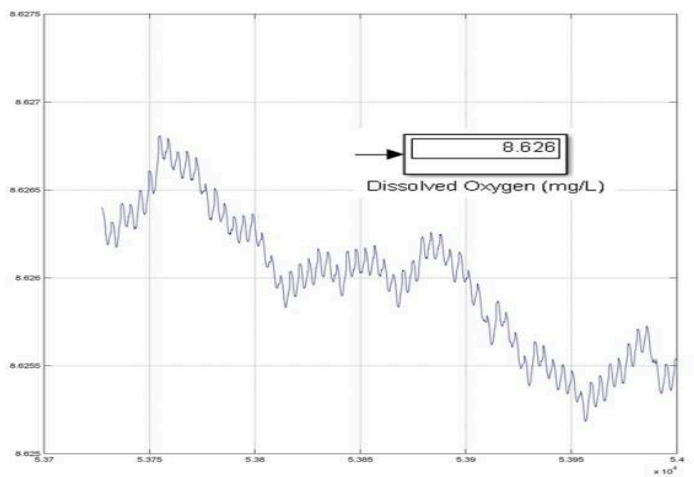

(c) Immerse at $50 \%$

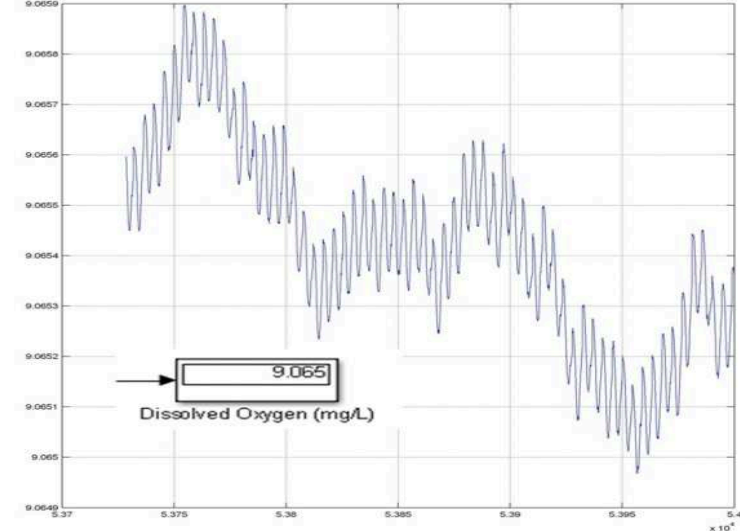

(b) Immerse at $25 \%$

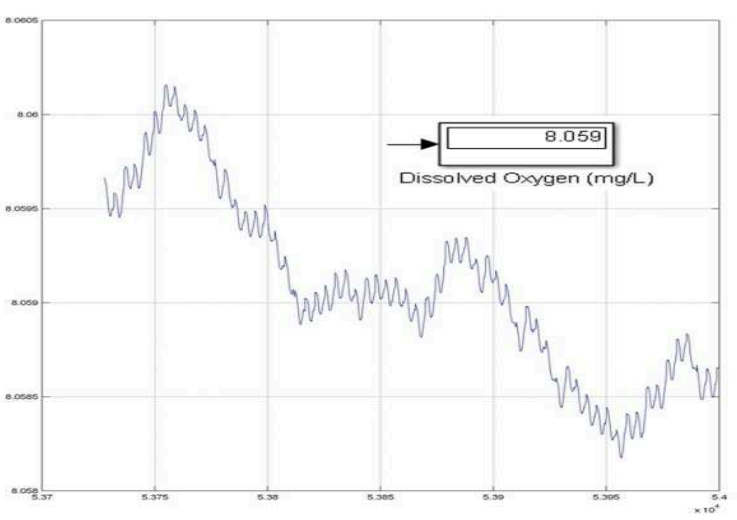

(d) Immerse at $75 \%$

Fig. 5: Simulation of estimated maximum Dissolved Oxygen with different level of immerse

\section{References}

[1] Gary L. Rogers "Aeration Offers Dealers More Than They May Realize". Volume 43 Number 6, June 2001

[2] Claude E.Boyd, Journal of Applied Aquaculture, Deep water installation of a diffused-air aeration system in a shallow pond, 1995

[3] James E. Kotoski, , Oxygen Minifact \& Analysis Sheet, 1997

[4] Deyzen A.V, (2008), A Nonlinear mathematical model of motions of planing monohull in head seas, Delft University of Technology, The Netherlands

[5] Benson T, (2010) Shape Effect on Drag, http:/www.grc.nasa.gov/WWW/k-12/airplane/ shaped.html. Last update Aug 23

[6] Azad A.K.M, Tokhi M.O, Mohamed Z, Mahil S and Poerwanto H (1994), Finite Different and finite element simulation 